\title{
Editorial
}

\section{The originality and specificity of medicinal product}

The long life of one medicinal product have multitude of influences and derogations of the common rules.

The nature of medicinal product it very singular. Pharmaceuticals are traditionally a high R\&D. The innovative process is characterized by extreme uncertainty. The implications of the development of the biotech generation represents an important discontinuity in the knowledge base used by pharmaceutical firms. The industry is composed by a series of fragmented, independent markets, called therapeutic categories. The largest firms hold dominant positions in individual TCs. There are one strong competition between innovators and imitators. Imitation plays a crucial role around existing molecules. Additionally, generic competition after patent expiration is becoming increasingly strong. Pharmaceuticals are, too, traditionally a marketing intensive sector. Marketing expenditures have an important role in accessing a large number of customers and the sensitivity of demand to price is rather low.

The pharmaceutical industry, has been deeply affected by a large variety of institutional factors and policies, ranging from different forms of regulation and organization of public research systems. The Governments and the National Health Services conditioning the prices. There are not free market. Practices of oligopoly and monopsony are frequent.

The essential aim of the rules governing the production, distribution and use of medicinal products are the safeguard of the public health.

Authorization must be subject to certain essential conditions. The documents which must accompany an application, for marketing authorization for a medicinal product, would demonstrate the quality, safety and efficacy of medicinal products. The potential risks are outweighed by the therapeutic efficacy of the product. The Risk-benefit balance are an evaluation of the positive therapeutic effects of the medicinal product in relation to the risks. The industry need to establish a Risk management system. In order to ensure the continued safety of medicinal products in use, it is necessary to ensure that pharmacovigilance systems are continually adapted to take account of scientific and technical progress.

There are, too, rules relating to the manufacture, control and inspection of medicinal products.

It is necessary to exercise control over the entire chain of distribution of medicinal products, from their manufacture through to supply to the public. These requirements will facilitate the withdrawal of defective products from the market and allow more effective efforts against counterfeit products. 
Other exigencies are necessary. Rules should be laid down as to how the labelling and package leaflets are to be presented. And the provisions governing the information supplied to users should provide a high degree of consumer protection, in order that medicinal products may be used correctly on the basis of full and comprehensible information. The Package leaflet containing information for the user which accompanies the medicinal product.

Advertising to the general public, even of non-prescription medicinal products, could affect public health, were it to be excessive and ill-considered. Advertising of medicinal products to the general public, where it is permitted, ought therefore to satisfy certain essential criteria which ought to be defined.

The advertising of medicinal products to persons qualified to prescribe or supply them contributes to the information available to such persons. Nevertheless, this advertising should be subject to strict conditions and effective monitoring.

Persons qualified to prescribe or supply medicinal products must have access to a neutral, objective source of information about products available on the market.

Liability for defective products it is regulated in all the countries. There are very big differences. Marketing authorisation holders, manufacturers and health professionals are subject to civil or administrative liability for any consequences resulting from the use of a medicinal product. Litigation weighs heavily on product safety and medical treatment.

Drug companies continuously analyze thousands of compounds, seeking ones of therapeutic value. During the six to seven years of preclinical testing, the manufacturer completes synthesis and purification of the drug and conducts limited animal testing to file an Investigational New Drug Application (IND). Clinical trials are the link between the results of pre-clinical testing and actual medical practice. They allow researchers to demonstrate the efficacy and safety of a new medicine or treatment, which is a prerequisite for marketing authorization. Without clinical trials a medicine could not be made available for treating patients. It is only through clinical trials that progress will be made on new medicines and improved treatment for diseases. Clinical Trials represent on average $58.6 \%$ of a product total development costs.

Review of the NDA typically lasts one to two years, bringing total drug development and approval to approximately nine years. Governments impose marketing restrictions through the approval processes and testing requirements.

Drug discovery is only the beginning of improved patient care. Once a drug is approved, adoption and use of new medicines and techniques requires responsible dissemination of information about these advances to the physicians who will evaluate them for their patients.

The documents accompanying an application for marketing authorisation shall be presented in accordance with the requirements content of the dossier, Common Technical Document (CTD). This presentation implements a common format for all ICH regions (European Community, United States of America, Japan). 
In 1990 was launched the International Conference of Harmonization (ICH), is a unique undertaking that brings together the drug regulatory authorities and the pharmaceutical industry of Europe, Japan and the United States. The ICH Parties are the founding members of ICH and represent the regulatory bodies and researchbased industry in the EU, US and Japan.

Harmonisation is achieved through the development of ICH Tripartite Guidelines. The Common Technical Document has been one of the more important agreement. In July 2003, the CTD became the mandatory format for new drug applications in the EU and Japan, and the strongly recommended format of choice for NDAs submitted to the PDA. Prepare all this documentation take years of work and his cost it is very high. In addition to permitting drugs on the market, the Agencies controls advertising and promotion.

At these moment, the period that elapses between the filing of an application for a patent for a new medicinal product and authorisation to place the medicinal product on the market makes the period of effective protection under the patent that insufficient to cover the investment put into the research. This situation leads to a lack of protection which penalises pharmaceutical research. Therefore, the provision of a supplementary protection certificate was necessary.

The "effective patent life" of a new drug is the time from approval to the end of the patent. When a patent expires, other producers are permitted to replicate the product and to sell it as a "generic drug." This competition drives down prices.

A patent, grants a degree of monopoly power to the patent holder. The usual term of patent life is twenty years.

During the 1970s and 1980s, the duration of requirements continued to grow, reducing the effective patent life. This situation leads to a lack of protection which penalises pharmaceutical research. Therefore, the provision of a supplementary protection certificate was necessary. In US, in 1984 the Patent Term Restoration Act extends patents. The extension is capped at a maximum of five years.

In the EU similar rules not was effective until the year1992 that was approved the Council Regulation (EEC) No 1768/92 of 18 June 1992 concerning the creation of a supplementary protection certificate for medicinal products. Then has been substantially amended several times.

The purpose of exclusivity rights granted to innovators is to create an incentive for research and development investments into new drugs. The industry depends uniquely on patent and Intellectual property right to support its investments in innovative activities. However, recent regulatory developments threaten the value of pharmaceutical intellectual property. Restrictions on competition in the market through price controls and other mechanisms will decrease expected returns during a product's patent life and thereby reduce incentives for investment in innovation.

With the government as a major payer for prescription drugs, with the increasing procurement role of other third parties, and the gradual transfer of product selection authority from physicians and pharmacists to hospital and managed-care administrators, the research-based industry must find new ways to make sure that its products are selected despite the increasing availability of cheaper generics. 
The patient's strongest safeguard is the competition for excellence among drug manufacturers and the freedom of his doctor and pharmacist to discriminate between good and bad products and to prescribe and dispense only the best and most suitable medicine to meet the patient's individual need.

The pharmaceutical marketing function is unique, too. There are multiple customer groups to manage. Others differences, from other industries is that several third parties, besides the manufacturer and consumer, are involved on both the demand and supply sides. The main pharmaceutical customer remains physicians, but patients, who are the end-users of the products, play an important role, as do insurers, governments and managed healthcare organisations. The consumer rarely pays the full price of the drug, with subsidies coining from governments, health insurance funds, and private insurance companies. They take part in pricing and reimbursement decisions.

Because of his unique characteristics of the pharmaceutical industry the drug market fails to meet the criteria for a perfectly competitive market. The pharmaceutical industry has complex characteristics. Regulating the pharmaceutical industry is a particularly difficult. At his complex characteristics on added that in the European Union pharmaceutical policy is still primarily determined at the national level.

Many EU directives have been adopted to achieve a single EU-wide pharmaceutical market. But variation in health system regimes across EU member states creates cross-country differences in prices for the same pharmaceutical product. The existence of the European Community market in pharmaceuticals it is only one objective in perspective.

In the pharmaceutical industry, there are market imperfections on both the demand and supply sides. In US there are not control of price but Federal agencies pay significantly different prices for the same prescription drugs because each agency and insurers uses a different approach to derive the payment rate. The federal and state governments are the largest purchasers of drugs, representing $40 \%$ of the total US pharmaceutical market.

In Europe, after the second World war most countries there established one or the other variant of a National health system. These programmes, which made monopsony buyers of governments, all include price controls or curtailments of supply. Monopsonistic characteristics of buyer bargaining power is imposed on the inputs of the free market economy.

For European governments, the monopsony power has allowed them to successfully counter the monopoly rent power of patent holders. The market for branded pharmaceuticals is closer to an oligopoly. This interaction are complex and give possibility at all type of corruptions. Demand are distorted by public and private insurance, and on behalf of the physicians. These institutional arrangements dominate economics, distorting the market for pharmaceuticals with important economic and ethical implications.

Governments determines drug prices, create price distortions with possible adverse implications for the health of drug companies. Pharmaceutical industry has 
criticised the central role of price control as an impediment to drug innovation and industry growth. Pharmaceuticals are indispensable to health systems. As pharmaceuticals have curative and therapeutic qualities, they are not ordinary commodities. (The industry depends uniquely on patent and Intellectual property right to support its in investments in innovative activities. However, recent regulatory developments threaten the value of pharmaceutical intellectual property.)

For all these reasons pharmaceuticals regulation are very differential character and specific dimensions.

Prof. José Luis Valverde

Editor in Chief 